\title{
Pigmented Adrenal Cortex Adenoma
}

National Cancer Institute

\section{Source}

National Cancer Institute. Pigmented Adrenal Cortex Adenoma. NCI Thesaurus. Code C4164.

A usually functioning adenoma of the adrenal cortex. Grossly, it has a dark brown appearance and is characterized by the presence of neoplastic cells containing abundant intracytoplasmic lipofuscin. It may be associated with Cushing syndrome. 